\title{
Differences in Hormonal Signaling Triggered by Two Root-Feeding Nematode Species Result in Contrasting Effects on Aphid Population Growth
}

\section{OPEN ACCESS}

Edited by:

Philip G. Hahn,

University of Montana, United States

Reviewed by:

Grace Anna Hoysted, University of Leeds, United Kingdom

Tina Kyndt,

Ghent University, Belgium

${ }^{*}$ Correspondence:

Nicole M. van Dam

nicole.vandam@idiv.de

Specialty section:

This article was submitted to Behavioral and Evolutionary Ecology,

a section of the journal

Frontiers in Ecology and Evolution

Received: 18 March 2018 Accepted: 04 June 2018

Published: 26 June 2018

Citation:

van Dam NM, Wondafrash M, Mathur V and Tytgat TOG (2018) Differences in Hormonal Signaling

Triggered by Two Root-Feeding Nematode Species Result in

Contrasting Effects on Aphid Population Growth.

Front. Ecol. Evol. 6:88 doi: 10.3389/fevo.2018.00088

\begin{abstract}
Nicole M. van Dam ${ }^{1,2,3 *}$, Mesfin Wondafrash ${ }^{1,4,5}$, Vartika Mathur ${ }^{6}$ and Tom O. G. Tytgat ${ }^{1}$
${ }^{1}$ Molecular Interaction Ecology, Institute of Water and Wetland Research, Radboud University, Nijmegen, Netherlands, ${ }^{2}$ German Centre for Integrative Biodiversity Research (iDiv) Halle-Jena-Leipzig, Leipzig, Germany, ${ }^{3}$ Institute of Ecology, Friedrich Schiller University Jena, Jena, Germany, ${ }^{4}$ Department of Zoology and Entomology, Forestry and Agricultural Biotechnology Institute, University of Pretoria, Pretoria, South Africa, ${ }^{5}$ School of Plant Sciences, Haramaya University, Dire Dawa, Ethiopia, ${ }^{6}$ Department of Zoology, Sri Venkateswara College, University of Delhi, New Delhi, India
\end{abstract}

Belowground feeding herbivores can affect their aboveground counterparts via systemic induced responses. Hormonal signaling pathways, such as the jasmonic acid (JA) and salicylic acid (SA) pathways, play a pivotal role in shaping such aboveground-belowground herbivore interactions. In this study, we analyzed the effects of two root-feeding nematode species, the cyst nematode Heterodera schachtii, and the root-knot nematode Meloidogyne hapla, on the preference and performance of cabbage aphid, Brevicoryne brassicae. The two sedentary nematodes differ in their feeding strategies and in which plant responses they trigger. We tested the hypothesis that differences in aphid preference and performance are governed by differences in systemic defense signaling triggered by the nematodes. When allowed to choose, aphids showed a lower preference for black mustard (Brassica nigra) plants infested with $\mathrm{H}$. schachtii compared to uninfested plants. On these plants their population increase was reduced as well. Gene expression analyses revealed that aphid infestation on $\mathrm{H}$. schachtii-infested plants strongly induced $P R 1$, a marker gene for the SA-pathway. The expression of the JA marker genes VSP2 and MYC2 was repressed. On the other hand, M. hapla infestation increased aphid preference and population growth compared to those on control plants. Aphid feeding upregulated the expression of VSP2 and MYC2, whereas PR1 expression was not induced. Interestingly, aphid infestation on plants without nematodes did not activate any of the signaling pathways. This suggests that $H$. schachtii infestation systemically enhanced aphid induced-resistance via the SA pathway. In contrast, $M$. hapla infestation enhanced JA-pathway regulated responses. This may reduce SA-induced resistance to aphid infestation via negative JA-SA cross-talk. Based on our results, we conclude that the differences in the interactions of aphids with cyst and root-knot nematodes emerge from differences in the plant responses triggered by both nematodes. Our results show that aboveground herbivore performance on plants infested with different nematode species may be strongly associated with nematode feeding strategies.

Keywords: aboveground-belowground interactions, Brevicoryne brassicae, induced defense responses, Heterodera schachtii, hormonal cross-talk, gene expression, Meloidogyne hapla, plant-herbivore interaction 


\section{INTRODUCTION}

Plants have evolved sophisticated defenses to a wide range of above- and belowground herbivores and pathogens. Some of these responses are induced upon damage, and thus can be tailored to the type of attacker (Karban and Baldwin, 1997; Mithöfer and Boland, 2008; Danner et al., 2017). Induced responses are mainly governed by the phytohormones jasmonic acid (JA), salicylic acid (SA), and ethylene (ET) (Beckers and Spoel, 2006). The JA pathway is commonly induced by chewing herbivores and necrotrophic pathogens, which cause tissue damage (Verhage et al., 2011; Wasternack, 2014). Biotrophic pathogens and sap-sucking insects such as aphids and whitefly, on the other hand, induce the SA pathway (Walling, 2000; Moran et al., 2002). ET has a modulatory role and acts synergistically with JA in Arabidopsis thaliana (Adie et al., 2007; Leon-Reyes et al., 2009). Plants respond very specifically to the type of herbivore or pathogen that is attacking. This involves an intricate receptor and signaling network, which fine-tunes the response based on specific cues (Koornneef and Pieterse, 2008; Wasternack, 2014). This specificity is caused by a combination of chemical and mechanical cues. First, the plants may recognize herbivores based on salivary compounds they excrete while feeding (Mithöfer and Boland, 2008). Second, herbivores with different feeding strategies, for example suckingpiercing aphids and leaf chewing caterpillars, induce or suppress different signaling pathways (Bidart-Bouzat and Kliebenstein, 2011). Each herbivore and pathogen induces its own combination of JA, SA, and ET responses. Cross-talk between the signaling pathways results in a specific defense response (Pieterse, 2012; Mathur et al., 2013a).

Induced responses do not only occur in the affected areas, but also modify the defense status of undamaged organs (Dicke and Baldwin, 2010; Karban, 2011; Mathur et al., 2013b). Systemic responses are triggered by signals transported via the air or the plant's vascular system (van Dam and Heil, 2011). They may either cause Induced Systemic Resistance (ISR), or prime the plant systemically (van Dam and Oomen, 2008; Erb et al., 2009). ISR increases the resistance levels of undamaged plant parts. Priming, on the other hand, enhances the induced response to later arriving herbivores or pathogens (Martinez-Medina et al., 2016). Both ISR and priming may cause interactions between aboveground and belowground herbivores feeding on the same plant (Erb et al., 2011; Mathur et al., 2011; van Dam and Heil, 2011; van Geem et al., 2016). Consequently, aboveground herbivores may be confronted with plant defense responses activated by root herbivores, and vice versa (Kaplan and Denno, 2007; Wurst et al., 2008; Kafle et al., 2017; Papadopoulou and van Dam, 2017). The outcome of aboveground-belowground interactions may depend on the herbivore species that is feeding on either organ, as well as on the time and sequence of infestation (Erb et al., 2011; van Dam and Heil, 2011).

Plant parasitic nematodes are known to infect thousands of species, causing economic losses of more than $\$ 157$ billion annually to global crop production (Abad et al., 2008). Sedentary cyst and root-knot nematodes are causing the greatest production losses (Jones et al., 2013). They parasitize plant roots by evading or suppressing host defenses (Sasser, 1989; Williamson and Kumar, 2006). Freshly hatched second stage juveniles (J2) migrate into the soil in search of a suitable host. By a combination of heavy stylet thrusting and release of cell wall degrading enzymes, the juveniles enter the root tissue close to the root tip at the elongation zone. Thereafter they migrate toward the vascular cylinder. Cyst and root-knot nematodes have different migration strategies which are essential for the interaction with their host plant. Cyst nematodes move intracellularly, thereby damaging root cells while moving to the vascular cylinder (Williamson and Gleason, 2003). Root-knot nematodes, on the other hand, move intercellulary through the cortex toward the root tip. In the root apex, they turn around, thereby damaging meristematic cells, and enter the vascular cylinder. In the vascular cylinder, they migrate again in a non-destructive way toward the differentiation zone (Williamson and Gleason, 2003). Both cyst and root-knot nematodes transform selected root cells into a permanent feeding site (Gheysen and Mitchum, 2011). Stylet secretions from the nematode pharyngeal glands are responsible for the induction of the feeding cell. Cyst and root-knot nematodes induce different feeding structures: cyst nematodes induce a syncytium, while root-knot nematodes induce the formation of giant cells (Gheysen and Mitchum, 2011). Throughout further development, the nematodes show a continuous cycle of alternate feeding on the cytoplasm and release of stylet secretions (Vanholme et al., 2004). In addition, nematodes manipulate hormonal signaling in their hosts in order to suppress defense responses and establish a sink for nutrients. As for aboveground herbivores, there is species-specificity among nematodes with regards to the hormonal pathways that are induced. This is also reflected in aboveground expression profiles. Plants infested with different nematodes show specific changes in the aboveground expression of signaling marker genes (Hamamouch et al., 2011). This suggests that, similar to aboveground herbivores, nematodes with different feeding strategies induce different signaling pathways in their host. In consequence, it can be postulated that nematodes with different invasion strategies, such as cyst and root-knot nematodes, have differential effects on aboveground feeding herbivores.

Like nematodes, aphids also feed directly on vascular tissue. When aphids arrive on their host plant they insert their stylets into the leaf tissue. On their way to the phloem, they puncture several mesophyll cells in which they inject salivary components or effectors (Hogenhout and Bos, 2011). The saliva of aphids contains enzymes such as peroxidases and $\beta$-glucosidases based on which plants may recognize aphids and respond accordingly (Miles, 1999; De Vos and Jander, 2009). As soon as the stylet is inserted into the phloem, aphids inject calcium-binding proteins to prevent blockage of the sieve elements (Hogenhout and Bos, 2011). Aphids are considered "stealthy feeders" (De Vos et al., 2005), because they elicit relatively few induced responses compared to chewing insects (Bidart-Bouzat and Kliebenstein, 2011; Danner et al., 2017). Next to causing little cell damage, they also inject effectors to reduce plant resistance responses (De Vos et al., 2005; Bidart-Bouzat and Kliebenstein, 2011; Hogenhout and Bos, 2011). Nevertheless, aphids can still be affected by (systemically) induced plant responses. For example, B. brassicae 
is a well-adapted specialist on Brassicaceae which even sequesters its specific defense chemicals, the glucosinolates, for its own defense (Francis et al., 2001). Despite these adaptations, its population development can be affected by nematode feeding (Kutyniok and Müller, 2013; Hol et al., 2016).

We hypothesized that differences in nematode feeding strategies affect the preference and performance of shoot feeding aphids. More specifically, we postulated that this specificity in the interactions between nematodes and aphids is reflected in aphidinduced defense signaling observed in the shoots. We tested our hypothesis using Brassica nigra infested with Heterodera schachtii, a cyst nematode, or Meloidogyne hapla, a root-knot nematode. Both nematodes are generalist pests on many crop species (Jones et al., 2013). They also occur naturally on B. nigra in low numbers ( $\mathrm{Hol}$ et al., 2016). We studied their effect on a common aboveground specialist aphid, Brevicoryne brassicae. To test our hypothesis, we set up a series of experiments. In all experiments, plants were infested with nematodes first. This mimics the natural sequence of events. Plant parasitic nematodes are amongst the first pests which an annual plant species, such as B. nigra, encounters. This is due to the fact that roots are the first tissues to emerge from the seed. Aphids generally arrive later in the life cycle of a plant, when sufficient leaf mass has formed (Kos et al., 2011). In natural environments, aphids are thus likely to encounter plants that are already infested by root nematodes. In our first experiment, we compared aphid population growth as affected by nematode infestation in a nochoice situation. In addition, we conducted a choice experiment in which aphids could choose between plants infested with a single nematode species and a control plant. We assessed both aphid preference within the first $48 \mathrm{~h}$ and long term aphid population development for up to 14 days. Finally, we designed an experiment to elucidate the signaling mechanisms underlying nematode-aphid interactions. Together, these three independent experiments allowed us to directly compare the ecological effects as well as underlying molecular mechanisms of the interactions between nematodes and the aphids.

\section{MATERIALS AND METHODS}

\section{Biological Materials Insect Culture}

A starting colony of cabbage aphid, Breviycoryne brassicae (L.) was obtained from the Laboratory of Entomology, Wageningen University and Research Centre, Wageningen, the Netherlands. This colony was maintained on black mustard, Brassica nigra, plants in insect cages in a greenhouse facility at Radboud University, Nijmegen, the Netherlands. A cohort of nymphs were obtained by transferring adult aphids from the maintenance culture to aphid free B. nigra plants. On the following day, the adult aphids were removed from the plants and only the newborn nymphs were maintained. Winged aphids (alates), which were required for host preference test, were obtained by crowding and starving the colonies.

\section{Plant Materials}

Brassica nigra seeds (collected in 2004 from population in Wageningen, see $\mathrm{Hol}$ et al., 2016) were germinated on water soaked glass pearls in $15 \times 10 \mathrm{~cm}$ plastic containers. The plastic containers were covered with transparent lids and kept in a climate chamber at a temperature of $20: 16^{\circ} \mathrm{C}$ (day: night) and a photoperiod of 16: $8 \mathrm{~h}$ (light: dark). After 10 days, the seedlings were transplanted to $1.5 \mathrm{~L}$ pots filled with river sand. Each of the plastic pots was filled with $2,000 \mathrm{~g}$ of dry river sand and supplied with $200 \mathrm{~mL}$ of tap water. Directly after transplantation, the pots received $100 \mathrm{~mL}$ half-strength Hoagland solution with three times phosphorus (3P Hoagland, see van Dam et al., 2004). Twenty randomly selected pots were weighed every 2 days in order to monitor the moisture content of the pots. The pots were supplied with water or Hoagland solutions to maintain the moisture content of the sand at $15 \%$. In cases where high variation in moisture content were observed among pots, the individual pots were weighed and supplied with water to bring the moisture content back to $15 \%$. The plants were supplied with Hoagland solution every week. Developmental stages of B. nigra plants were determined following a universal $\mathrm{BBCH}$ scale (Lancashire et al., 1991).

\section{Nematode Cultures}

Second stage infective juveniles (J2s) of Heterodera schachtii and Meloidogyne hapla were purchased from HZPC Research and Development, Metslawier, the Netherlands. The nematodes were hatched in root exudates, then purified and shortly stored in tap water. The concentration of each nematode species was determined by counting the number of $\mathrm{J} 2 \mathrm{~s}$ per $1 \mathrm{~mL}$ of nematode suspension under a stereomicroscope.

\section{Experiments}

\section{Aphid No-Choice Performance Experiment}

Ten 4 -weeks old $B$. nigra plants, each with two visibly extended internodes (BBCH code 32) were assigned to each of the following three treatment groups: Aphids only, Aphids + H. schachtii, Aphids + M. hapla. Prior to nematode inoculation, plants were supplied with Hoagland solution so that the plants were well watered at the time of nematode infection. Following this, each of the plants in the Aphids $+H$. schachtii and Aphids + M. hapla groups were inoculated with $3 \mathrm{~mL}$ water containing in total $750 \mathrm{~J} 2 \mathrm{~s}$ of $\mathrm{H}$. schachtii or M. hapla, respectively. Plants in the first treatment group were mock inoculated with the same volume of water. The nematode suspension was injected into the sand mass close to the rhizosphere. After inoculation, $50 \mathrm{~mL}$ of water was supplied to each of the plants in order to facilitate the distribution of nematodes in the rhizosphere. On the seventh day after nematode inoculation, all plants were transferred to individual insect cages. Five 2 -days old B. brassicae nymphs were released on the top three fully unfolded leaves of each of the thirty B. nigra plants. At this time point, the plants had four extended internodes ( $\mathrm{BBCH}$ code 34$)$. The performance of the aphids was determined over the next 28 days by counting aphids at day $7,11,14,17,20,23,26$, and 28 . At day 35 , the plants were harvested and shoots were immediately freeze-dried to determine their biomass. The number of nematodes present on the roots of each plant were counted and the roots freeze-dried for biomass measurement. 


\section{Aphid Choice and Performance Experiment}

Two separate choice experiments were conducted to study the preference of $B$. brassicae alates for $H$. schachtii and $M$. hapla infected $B$. nigra plants and their subsequent performance. In the first experiment, ten pairs of plants were kept in a cage. One plant was inoculated with $1000 \mathrm{~J} 2 \mathrm{~s}$ of $H$. schachtii in $4 \mathrm{~mL}$ water and the other was mock inoculated with $4 \mathrm{~mL}$ water. On the seventh day after nematode inoculation, 10 winged aphids (alates) were released in each cage in a plastic Petri dish placed equidistant from the two plants. In the second experiment, a similar set-up was used with only four pairs of plants, due to a paucity of plant materials. One was inoculated with $1000 \mathrm{~J} 2 \mathrm{~s}$ of M. hapla and the other mock inoculated. Seven days later, 20 alates were released in each cage. The preference of $B$. brassicae for nematode infected vs. nematode-free plants was assessed by counting the number of winged aphids that had landed on the plants at 16, 24, 40, and $48 \mathrm{~h}$. After aphid preference assessment, the plants were maintained as pairs in the same cages. Aphid numbers were counted at 5, 8, 11, and 14 days after aphid release.

\section{Gene Expression in Response to Nematode and Aphid Infestation}

Four-weeks old $B$. nigra plants with two visibly extended internodes (BBCH code 32) were assigned to each of the following six treatment groups: nematode and aphid free plants (Control); only H. schachtii inoculated in the roots (Hs), only $M$. hapla inoculated in the roots (Mh), only B. brassicae aphids released on the shoot (BB), $H$. schachtii inoculated in the roots and aphids released on the shoot $(\mathrm{Hs}+\mathrm{BB})$, M. hapla inoculated in the roots and aphids released on the shoot $(\mathrm{Mh}+\mathrm{BB})$. Each of the plants receiving nematode treatments were inoculated with $750 \mathrm{~J} 2 \mathrm{~s}$ of the respective nematode species as above. On the seventh day after nematode inoculation, five developmentally synchronized $B$. brassicae nymphs were released on $B$. nigra plants in $\mathrm{BB}, \mathrm{Hs}+\mathrm{BB}$ and $\mathrm{Mh}+\mathrm{BB}$ treatment groups. Plants were harvested for gene expression analyses on the third, seventh (just prior to aphid infestation) and sixteenth day (9 days after aphid release) of nematode inoculation. For each time point, ten plants were harvested from each treatment group.

Leaves of the harvested plants were snap frozen in liquid nitrogen, stored at $-80^{\circ} \mathrm{C}$ and freeze-dried. The dried samples were ground with a Retsch Mixer Mill MM300 (Retsch GmbH, Rheinische, Germany) using stainless steel balls. Total RNA was extracted with Aurum ${ }^{\mathrm{TM}}$ Total RNA Mini Kit (BioRad, Berkeley, USA) with an additional DNase treatment step included. The number of samples per treatment was reduced from ten to five by pooling two samples together in order to reduce biological variation. The RNA quality and absence of genomic DNA was checked on agarose gel. The concentration and quality of RNA was determined by Nanodrop (Thermo Fisher Scientific, Wilmington, U.S.A.). A 500 ng aliquot of total RNA was reverse transcribed using the iScript ${ }^{\mathrm{TM}} \mathrm{cDNA}$ Synthesis Kit (Bio-Rad, Berkeley, USA). Prior to qPCR, the cDNA was diluted to 20 -fold. To verify the absence of genomic DNA contamination, negative cDNA control samples were made by omitting the reverse transcriptase.
Expression levels of three plant defense-related marker genes: PR1, for the SA pathway (Fu and Dong, 2013), plus MYC2 and VSP2 as JA responsive genes (Pieterse et al., 2009; Verhage et al., 2011) were analyzed along with three Brassica internal control genes: GAPC2, PP2A and SAND (Table 1). Real-time amplification reactions were performed using SYBR Green detection method on 96-well plates with the BioRad iCycler thermocycler (BIO-RAD, Hercules, CA, USA). Amplification reactions were performed in a $25 \mu \mathrm{L}$ reaction solution comprising $12.5 \mu \mathrm{L}$ of $\mathrm{iQ}^{\mathrm{TM}} \mathrm{SYBR}^{\circledR}$ Green Supermix (BIO-RAD, Hercules, CA, USA), $0.75 \mu \mathrm{L}(10 \mu \mathrm{M})$ of each of primer, $6 \mu \mathrm{L}$ of nuclease free water and $5 \mu \mathrm{L}$ of the template cDNA. A control reaction was run for each gene where the cDNA was replaced by nuclease free water. The reactions were run for 45 cycles at $95^{\circ} \mathrm{C}$ for $3 \mathrm{~min}, 95^{\circ} \mathrm{C}$ for $30 \mathrm{~s}, 60^{\circ} \mathrm{C}$ for $15 \mathrm{~s}$ (except for VSP2 gene where the annealing temperature was $61^{\circ} \mathrm{C}$ ) and $72^{\circ} \mathrm{C}$ for $15 \mathrm{~s}$ and followed by a melting curve analysis of $1 \mathrm{~min}$ at $95^{\circ} \mathrm{C}, 1 \mathrm{~min}$ at $55^{\circ} \mathrm{C}$ and $10 \mathrm{~s}$ at $55^{\circ} \mathrm{C}+0.5^{\circ} \mathrm{C}$ each cycle for 80 cycles. For all target and reference genes, orthologous Arabidopsis thaliana locus numbers and primer sequences are shown in Table 1.

\section{Data Analysis}

\section{No Choice Experiment}

To detect differences in aphid population growth in the nochoice experiment, aphid numbers over time were analyzed using repeated measures ANOVA with a Greenhouse-Geisser correction to correct for lack of sphericity of the data.

\section{Choice Experiment and Population Development}

Aphid preference and performance data obtained in the choice experiments were analyzed using replicated $G$-tests (Sokal and Rohlf, 1995). This allowed us to analyze overall distribution of aphids over pairs of control and nematode infested plants $\left(G_{p}\right.$, equivalent to Chi-square), as well as the total fit of the data to a 1:1 distribution $\left(\mathrm{G}_{t}\right)$. Gp or Chi-square values are based on overall numbers; the sums of rows and columns in the distribution table. The $G_{t}$ value, however, takes into account that the experiment consisted of multiple replicates, in this case plant pairs. The $G$-test also allows to identify heterogeneity among the replicates $\left(G_{h}\right.$; Sokal and Rohlf, 1995). For the longer term population analyses (5-14 days) the paired set-up of control and nematode infested plants was continued. The aphid counts over the experiment are thus a combination of per plant aphid population growth plus redistribution of aphids over the two plants. For this reason, the distribution of aphids at the end of the experiment (day 14) were also analyzed using $G$-tests.

\section{Plant Biomass and Numbers of Galls/Cysts}

Biomass data and numbers of cysts/galls were analyzed using ANOVAs per treatment group using SPSS 20.0 (SPSS, Chicago, IL, USA). Gene expression data: primer pair efficiencies were calculated using LinRegPCR (11.0) program (Ramakers et al., 2003). Expression levels of target genes were determined by normalizing over the expression levels of three reference genes (GAPC2, PP2A and SAND). The expression of the reference genes was computed using the average of mean 


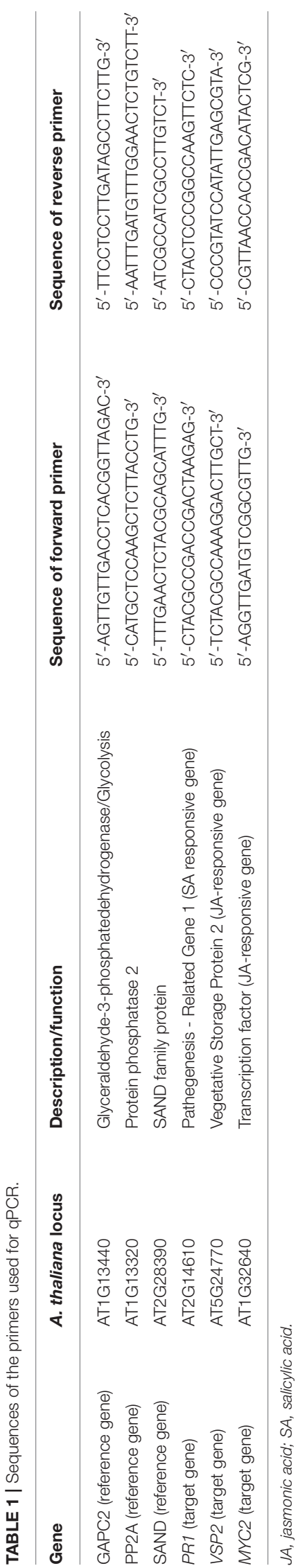

PCR efficiency and geometric mean of each reference gene (Vandesompele et al., 2002). Normalized expressions of the target genes were then calculated by dividing the expression of the reference genes by that of the target gene (Muller et al., 2002). The normalized expression values of the control groups were averaged. These averages were used to calculate Log2 expression data for each treatment group as follows: Log2 expression $=$ Log2(ExpressionSample_norm/AverageControl_ norm). For each treatment group, it was tested whether Log2 expression values deviated from 0 i.e., whether the gene was significantly up or down regulated, by a single sample $t$-test. To control for multiple comparisons we set alpha to 0.005 . Data were checked for normality (Kolmogorov Smirnov test on residuals) and Homogeneity of Variance (HOV; Levene's test) and analyzed with ANOVA. When data did not meet requirements (e.g., $P R 1$ expression on day 16), the equivalent non-parametric Kruskall-Wallis analysis was applied. All gene expression data were analyzed using Statistica version 12.7 (StatSoft Europe, Hamburg, Germany). Tukey HSD tests were conducted to identify significant differences among treatments within harvest.

\section{RESULTS}

\section{Aphid No-Choice Performance Experiment}

Aphid population increase on nematode infected B. nigra plants was not significantly different from that on nematode-free plants (Figure 1; Repeated measures ANOVA, Treatment: $F=1.199$, $p=0.318$; Treatment $\times$ Time: $F=2.119, p=0.357)$. However, on $H$. schachtii infected plants, aphid population numbers were consistently lower. The numbers of root cysts (adult females) and root galls on $H$. schachtii and M. hapla inoculated plants, respectively, did not significantly differ between plants with and without aphids (Table 2; $p=0.436$ ). In the H. schachtii treatment group, the number of aphids per plant counted at the end of the experiment decreased with the number of cysts [Figure 1, Table 2; aphids $=-24.94 \ln$ (cysts) $\left.+103.08, R^{2}=0.3947\right]$. No correlation was found between aphids and root galls in the $M$. hapla treatment group. Herbivory by aphids and nematodes, alone or in combination, did not significantly affect plant total dry biomass (Table 3; ANOVA, $F=2.214$; $d f=5 ; p=0.066$ ), shoot $(F=2.065, d f=5 ; p=0.084)$ or root dry biomass $(F=1.098, d f=5 ; p=0.372)$.

\section{Aphid Choice and Performance Experiment}

We conducted a choice experiment to determine host preference of winged B. brassicae. This mimics the natural situation, where winged aphids (alates) select suitable host plants to establish and reproduce. When given the choice, significantly lower numbers of aphids were counted on $H$. schachtii infected plants at all time points, except for $40 \mathrm{~h}$ after aphid release, compared to nematode-free plants (Figure 2A; Table 4). In contrast, higher numbers of $B$. brassicae alates landed on $M$. hapla infected plants at $16 \mathrm{~h}$ after their release (Figure $3 \mathrm{~A}$ ).

The plant pairs were maintained in the same net cages and the population size of $B$. brassicae was counted at 5, 8, 11, and 14 days after aphid release. The average number of aphids on controls 


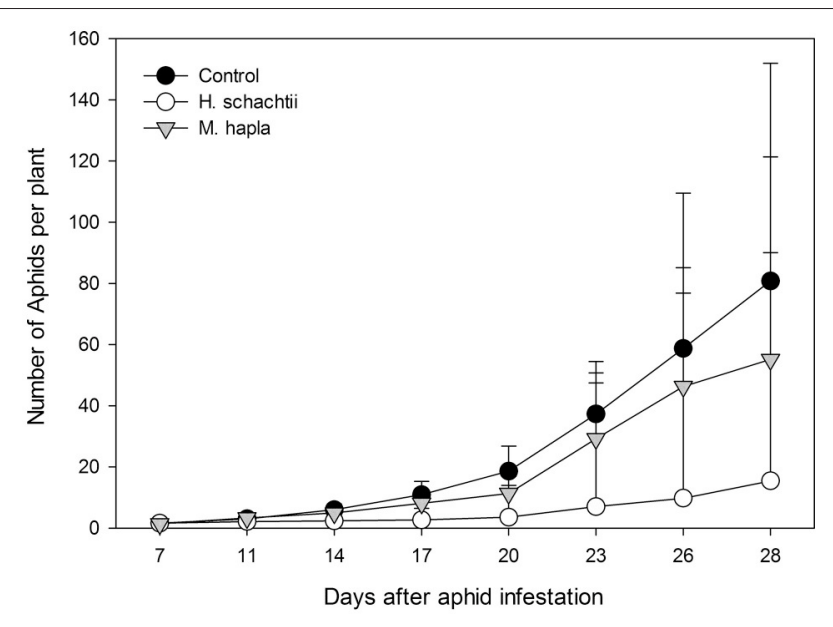

FIGURE 1 | Average numbers ( \pm SEM) of Brevicoryne brassicae aphids found per plant from 7 to 28 days after five 2-day old nymphs were released on each plant (no-choice experiment; $n=10$ per treatment group). Plants were either infested with Heterodera schachtii (white circles) or Meloidogyne hapla (gray triangles) or mock inoculated (black squares) 7 days before aphids were released.

TABLE 2 | Average number \pm SEM of cysts (Heterodera schachtii) or root galls (Meloidogyne hapla) per plant at 16 days after infestation with nematodes on plants with and without 9 days of aphid (Brevicoryne brassicae) feeding.

\begin{tabular}{lcc}
\hline & No aphids & With aphids (B. brassicae) \\
\hline Heterodera schachtii & $37.6 \pm 5.6$ & $37.8 \pm 6.9$ \\
Meloidogyne hapla & $28.6 \pm 4.1$ & $28.9 \pm 4.4$ \\
\hline
\end{tabular}

$N=10$ per treatment group.

was larger than on $H$. schachtii infested plants at each time point (Figure 2B). After 14 days, control plants supported 1.5 times more aphids than $H$. schachtii-infested plants (Figure 2B, G-test, $\mathrm{Gt}=305.7$, d.f. $=4, p<0.001$ ). The opposite pattern was observed for the control-M. hapla pairs; after 14 days $M$. hapla plants overall hosted about twice as many aphids as controls ( $G$ test, $\mathrm{Gt}=1409.15$, d.f. $=10, p<0.001)$. We found considerable variance in the numbers of aphids per plants (Figures 2, 3), as well as significant heterogeneity in aphid distribution among the plant pairs (Table 4; $H$. schachtii pairs: $G h=1181$, d.f. $=9$, $p<0.001 ;$ M. hapla pairs, $\mathrm{Gh}=63.8$, d.f $=3, p<0.001$ ).

\section{Gene Expression in Response to Nematode and Aphid Infestation}

To analyze how nematodes affect shoot defense responses to aphid infestation, we analyzed the expression of three marker genes before and after aphid infestation. We chose PR1 as a marker for the SA pathway. MYC2 and VSP2 served as marker genes for the JA signaling pathway. Both nematodes similarly affected $P R 1$ expression over time (Figure 4A). At 3 d.a.i., $P R 1$ expression levels in nematode-infested plants were similar to those in control plants. At 7 d.a.i. both nematode species reduced $P R 1$ expression, whereas they increased $P R 1$ expression at 16 d.a.i. Nine days of aphid infestation alone did not affect $P R 1$ expression (Figure 4A). However, when the aphids were feeding on plants infested with $H$. schachtii, the PR1 expression in the shoots was significantly higher than that in plants with aphids only. In contrast, PR1 expression in plants with aphids and $M$. hapla nematodes were close to control levels and significantly lower than on plants with M. hapla only (Figure 4A).

Early MYC2 expression at 3 d.a.i. differed between nematode species; H. schachtii downregulated MYC2, whereas M. hapla increased its expression (Figure 4B). Interestingly, VSP2, which is downstream of MYC2, was significantly suppressed in both nematode treatments at the same time point (Figure 4C). At 7 d.a.i., the difference had disappeared and both nematode species downregulated MYC2 and VSP2 expression. This changed again at 16 d.a.i.; $H$. schachtii upregulated both MYC2 and VSP2, whereas $M$. hapla downregulated both genes. Aphid feeding alone did not upregulate MYC2 or VSP2 over control levels (Figures 4B,C). However, when aphids were on plants with $H$. schachtii, the expression of both JA-marker genes was downregulated and lower than in plants with aphids or $H$. schachtii only (Figures $4 \mathrm{~B}, \mathrm{C}$ ). In contrast, aphid feeding on plants with M. hapla upregulated the expression of MYC2 and, even more so, of VSP2. This resulted in higher expression of these JA-markers than in plants with aphids or M. hapla only (Figures 4B,C).

\section{DISCUSSION}

Our results show that two species of nematodes with different feeding strategies affect the preference and performance of aboveground feeding aphids in opposite ways. The effects became most apparent when the aphids could choose between noninfected (control) and nematode-infected plants. Infestation by the cyst nematode $H$. schachtii had a negative impact on aphid preference and population growth. In contrast, M. hapla infestation attracted aphids and made $B$. nigra a more suitable host. Gene expression analyses revealed that these disparate effects are likely caused by differences in the systemically induced responses triggered by both nematodes. Nine days of aphid feeding more strongly upregulated PR1 expression on plants infested with $H$. schachtii than on nematode-free plants. $M$. hapla feeding, on the other hand, reduced PR1 expression, but upregulated the JA marker genes VSP2 and MYC2. This means that $M$. hapla may suppress SA related responses triggered by aphids, most likely via negative cross-talk by enhancing the JA pathway. Together our results confirm the hypothesis that differences in nematode feeding strategies affect systemic effects on aboveground herbivores via differential elicitation of hormonal signaling pathways.

\section{Systemic Responses to Nematode Infestation}

Most studies analyzing aboveground-belowground interactions between defense responses analyze systemic responses to belowground insect herbivores or microbial pathogens (van Dam and Heil, 2011; Biere and Goverse, 2016). Compared to this large body of literature, relatively few studies consider how 
TABLE 3 | Brassica nigra shoot, root and total plant biomass (g dry mass) \pm SEM at 16 days after infestation with Heterodera schachtii or Meloidogyne hapla of plants with and without 9 days of aphid (Brevicoryne brassicae) feeding.

\begin{tabular}{|c|c|c|c|c|c|c|}
\hline & \multicolumn{3}{|c|}{ No aphids } & \multicolumn{3}{|c|}{ With aphids (B. brassicae) } \\
\hline & Shoot & Root & Total & Shoot & Root & Total \\
\hline Control & $4.33 \pm 0.43$ & $1.01 \pm 0.15$ & $5.34 \pm 0.44$ & $4.77 \pm 0.48$ & $1.12 \pm 0.23$ & $5.88 \pm 0.52$ \\
\hline H. schachtii & $4.77 \pm 0.53$ & $0.95 \pm 0.16$ & $5.73 \pm 0.48$ & $4.55 \pm 0.44$ & $1.09 \pm 0.21$ & $5.64 \pm 0.43$ \\
\hline M. hapla & $4.34 \pm 0.32$ & $1.10 \pm 0.18$ & $5.45 \pm 0.29$ & $4.76 \pm 0.44$ & $1.10 \pm 0.17$ & $5.86 \pm 0.48$ \\
\hline
\end{tabular}

$N=10$ per treatment group.
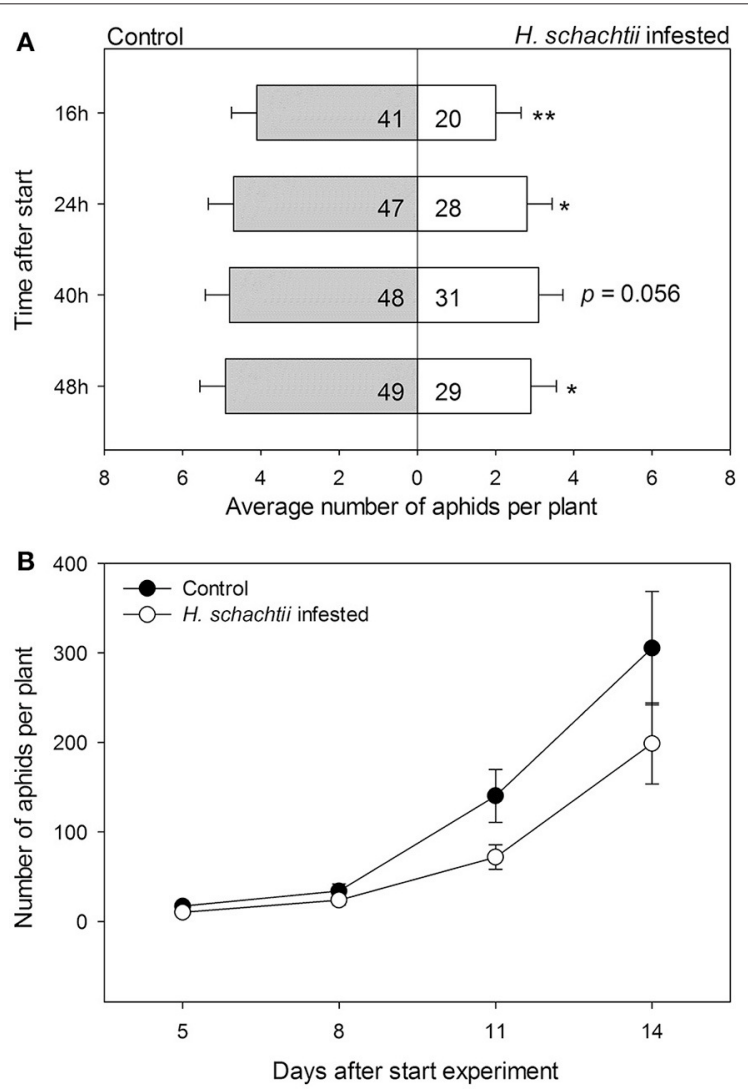

FIGURE 2 | Average numbers ( \pm SEM) of Brevicoryne brassicae aphids found per plant. (A) Number of aphids at 16, 24, 40, and 48h after 10 winged aphids were released in each cage $(n=10)$. The aphids were allowed to choose between a control plant (gray bars) and a plant infested with Heterodera schachtii nematodes (white bars) enclosed in a single cage. In the bars: sum of aphids out of 100 released in total found on plants in the respective treatment group. The remaining aphids were not found on any plant at the times the aphids were counted. The asterisks indicate whether the distributions of the aphids overall were deviating from a 1:1 distribution (replicated G-test per time point, Gpooled, d.f. =1); ${ }^{\star} p<0.05,{ }^{* *} p<0.01$. (B) Numbers of aphids on either plant from 5 to 14 days after aphids were released. Black circles: control plants, white circles: $H$. schachtii infested plants. Both plants were left in the same insect cage over the course of the experiment; the resulting numbers thus are a combination of growth rates and redistribution of aphids.

nematode-infestation alters the expression of defense related genes in the leaves (Biere and Goverse, 2016). We found that the cyst nematode $H$. schachtii first suppresses (3-7 d.a.i), and then increases PR1 expression at 16 d.a.i.. In line with our findings, the cyst nematode Globodera pallida increased endogenous SA concentrations 14 d.a.i. in Solanum tuberosum (Hoysted et al., 2017). In this study, the expression of three PR genes (PR1, PR2, and PR5) serving as markers for SA signaling (Fu and Dong, 2013) were analyzed. Only PR5 was significantly upregulated by cyst nematode infestation. Endogenous JA levels were not changed by G. pallida infestation (Hoysted et al., 2017). This contrasts with our observation that $H$. schachtii first downregulated ( 3 and 7 d.a.i) and then upregulated the JA marker genes MYC2 and VSP2 at 16 d.a.i.. M. hapla infestation caused a similar expression profile for $P R 1$ as $H$. schachtii. However, M. hapla mostly suppressed JA marker expression over the course of the experiment, with exception of MYC2 at 3 d.a.i. The M. hapla-induced PR1 expression in leaves contrasts with previous studies. Root-knot nematodes, especially Meloidogyne spp., generally suppress leaf defenses, independently of the response they induce in the root (Hamamouch et al., 2011). However, which pathways are affected, and how, varies among studies. In rice, M. graminicola infestation suppresses both SA and JA pathways in the leaves starting from 3 d.a.i. onwards (Kyndt et al., 2012b). Similarly, several SA and JA marker genes are suppressed in the leaves of A. thaliana infested for 514 days with $M$. incognita (Hamamouch et al., 2011). Direct measurements of the hormone concentrations in S. lycopersicum showed a lower endogenous SA, but higher JA concentrations in the leaves at 14 d.a.i. with M. incognita (Kafle et al., 2017). Due to a paucity of studies, it is currently not possible to identify general patterns. More detailed analyses of the effectors that the different nematodes excrete may shed more light on how they differentially manipulate their host's defense response (Vanholme et al., 2004; Abad et al., 2008; Haegeman et al., 2012).

\section{Interactive Effects of Nematodes and Aphids}

Once aphids were feeding on the nematode infected plants, we found a clear difference in the activation of signaling pathways between $H$. schachtii and $M$. hapla infested plants. $H$. schachtii infestation strongly enhanced PR1 expression upon aphid feeding. A similar activation of the SA defense pathway, as indicated by an increase in endogenous SA concentration, was observed in S. tuberosum when plants were infected with the cyst nematode G. pallida and the aphid Myzus persicae (Hoysted et al., 2017). On the other hand, MYC2 and VSP2 expression 


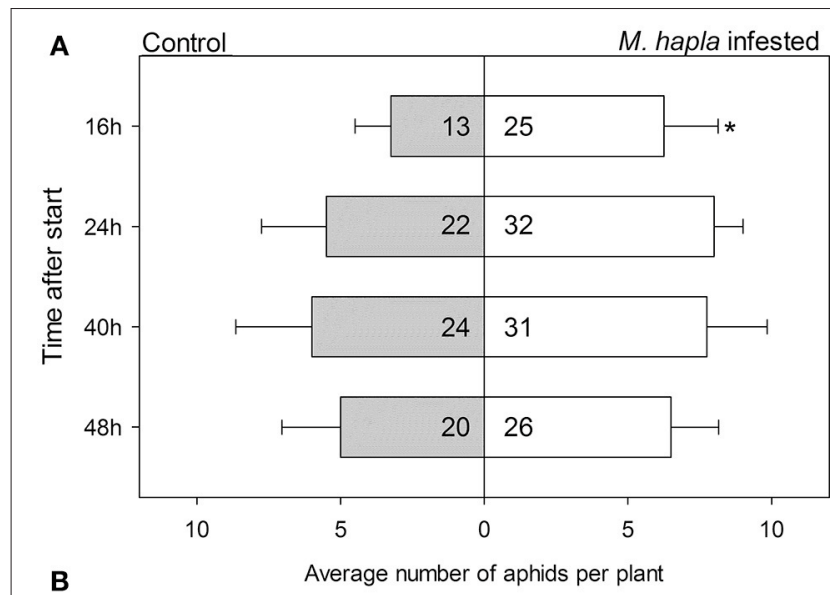

B

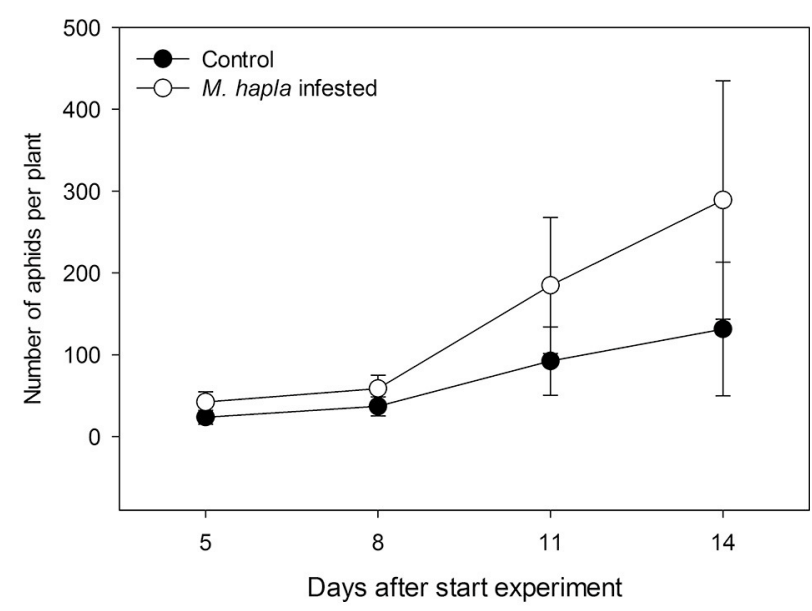

FIGURE 3 | Average numbers ( \pm SEM) of Brevicoryne brassicae aphids found per plant. (A) Number of aphids at 16, 24, 40, and 48 h after 20 winged aphids were released in each cage $(n=4)$. The aphids were allowed to choose between a control plant (gray bars) and a plant infested with Meloidogyne hapla nematodes (white bars) enclosed in a single cage. In the bars: sum of aphids out of 80 released in total found on plants in the respective treatment group. The remaining aphids were not found on any plant at the times the aphids were counted. The asterisks indicate whether the distributions of the aphids overall were deviating from a 1:1 distribution (replicated G-test per time point, Gpooled, d.f. $=1$ ); ${ }^{*} p<0.05$. (B) Numbers of aphids on either plant from 5 to 14 days after aphids were released. Black circles: control plants, white circles: M. hapla infested plants. Both plants were left in the same insect cage over the course of the experiment; the resulting numbers thus are a combination of growth rates and redistribution of aphids.

were suppressed on double infested plants, compared to plants infested with $H$. schachtii or the aphid alone. Interestingly, the aphid-induced suppression of VSP2 was the strongest in the presence of $H$. schachtii, which on its own strongly increased VSP2 expression. This indicates that the enhanced SA-response induced by aphids on $H$. schachtii-infested plants may suppress the JA-induced responses via negative cross-talk (Pieterse et al., 2009). In contrast, aphid feeding on M. hapla-infested plants induced the JA, but not the SA pathway. Indeed, it has been reported that aphid feeding triggers both SA and JA responses (Moran et al., 2002; De Vos et al., 2005; Cao et al., 2016). On Arabidopsis thaliana, B. brassicae feeding particularly increases
TABLE 4 | G-test test values for the Brevicoryne brassicae choice tests; short term distribution.

\begin{tabular}{|c|c|c|c|c|c|c|c|}
\hline & \multicolumn{3}{|c|}{ Control vs. H. schachtii } & & \multicolumn{3}{|c|}{ Control vs. M. hapla } \\
\hline & Gh & Gp & Gt & & Gh & Gp & Gt \\
\hline & 9 d.f. & 1 d.f. & 10 d.f. & & 3 d.f. & 1 d.f. & 4 d.f. \\
\hline $16 \mathrm{~h}$ & 229.52 & 7.36 & 236.88 & $16 \mathrm{~h}$ & 14.49 & 3.85 & 18.33 \\
\hline$P$ & $<0.001$ & 0.0067 & $<0.001$ & $p$ & $<0.001$ & 0.049 & $<0.001$ \\
\hline $24 \mathrm{~h}$ & 267.88 & 4.85 & 272.74 & $24 \mathrm{~h}$ & 10.22 & 1.86 & 12.09 \\
\hline$P$ & $<0.001$ & 0.0276 & $<0.001$ & $p$ & 0.017 & 0.172 & 0.017 \\
\hline $40 \mathrm{~h}$ & 279.22 & 3.64 & 282.86 & $40 \mathrm{~h}$ & 22.30 & 0.89 & 23.19 \\
\hline$P$ & $<0.001$ & 0.0564 & $<0.001$ & $p$ & $<0.001$ & 0.345 & $<0.001$ \\
\hline $48 \mathrm{~h}$ & 279.73 & 5.18 & 284.91 & $48 \mathrm{~h}$ & 13.28 & 0.78 & 14.07 \\
\hline$p$ & $<0.001$ & 0.0228 & $<0.001$ & $p$ & $<0.001$ & 0.376 & 0.007 \\
\hline
\end{tabular}

d.f, degrees of freedom; Gh, G for heterogeneity among test replicates; Gp, G for pooled data (equivalent to Chi-square analysis on total numbers per treatment group); Gt, G for overall fit of the expected ratios (1:1); H. schachtii, plants infested with Heterodera schachtii nematodes; M. hapla, idem, with Meloidogyne hapla nematodes.

the expression of genes in the SA pathway, and to a lesser extent in the JA pathway (Kuśnierczyk et al., 2008). Interestingly, PR1 expression was found to be only upregulated at later time points (24-48 h after aphid infestation). VSP2 expression was downregulated by aphid feeding in A. thaliana, despite the general upregulation of JA-related genes (Kuśnierczyk et al., 2008). In our study, we found that the specialist B. brassicae on its own induced very few defense responses, as indicated by marker gene expression. However, this does not preclude that plant defense levels are locally increased. Both $B$. brassicae and $M y$. persicae feeding can up-or downregulate the levels of specific glucosinolates in leaves and phloem of $A$. thaliana and Brassica species (Kutyniok and Müller, 2012; Hol et al., 2013, 2016). Aphids, like nematodes, inject salivary components to manipulate their host's defense responses and to create a sink at their feeding site (De Vos and Jander, 2009). A reallocation of glucosinolates as a consequence of these manipulations, may require the action of glucosinolate transporters (Nour-Eldin et al., 2012), rather than the activation of glucosinolate biosynthesis genes via the SA or JA-signaling pathway.

\section{Molecular Mechanisms Underlying Interactive Effects}

The differential effects of the two nematodes species on aphidinduced responses in the shoots, may originate from differences in the specific plant-nematode interaction. As mentioned above, root-knot nematodes invade the plant causing little cell damage. Cyst nematodes, on the other hand, damage root cells while migrating to the vascular cylinder (Gheysen and Mitchum, 2011). The damage caused by $H$. schachtii in the early phases of the plant-nematode interaction, may have primed the plant to respond stronger to the later arriving aphids. When priming occurs, there may first be an initial response to the priming stimulus, in this case the nematode infestation (see MartinezMedina et al., 2016). Indeed, M. hapla infested plants showed upregulated MYC2 and, to a lesser extent PR1, expression 


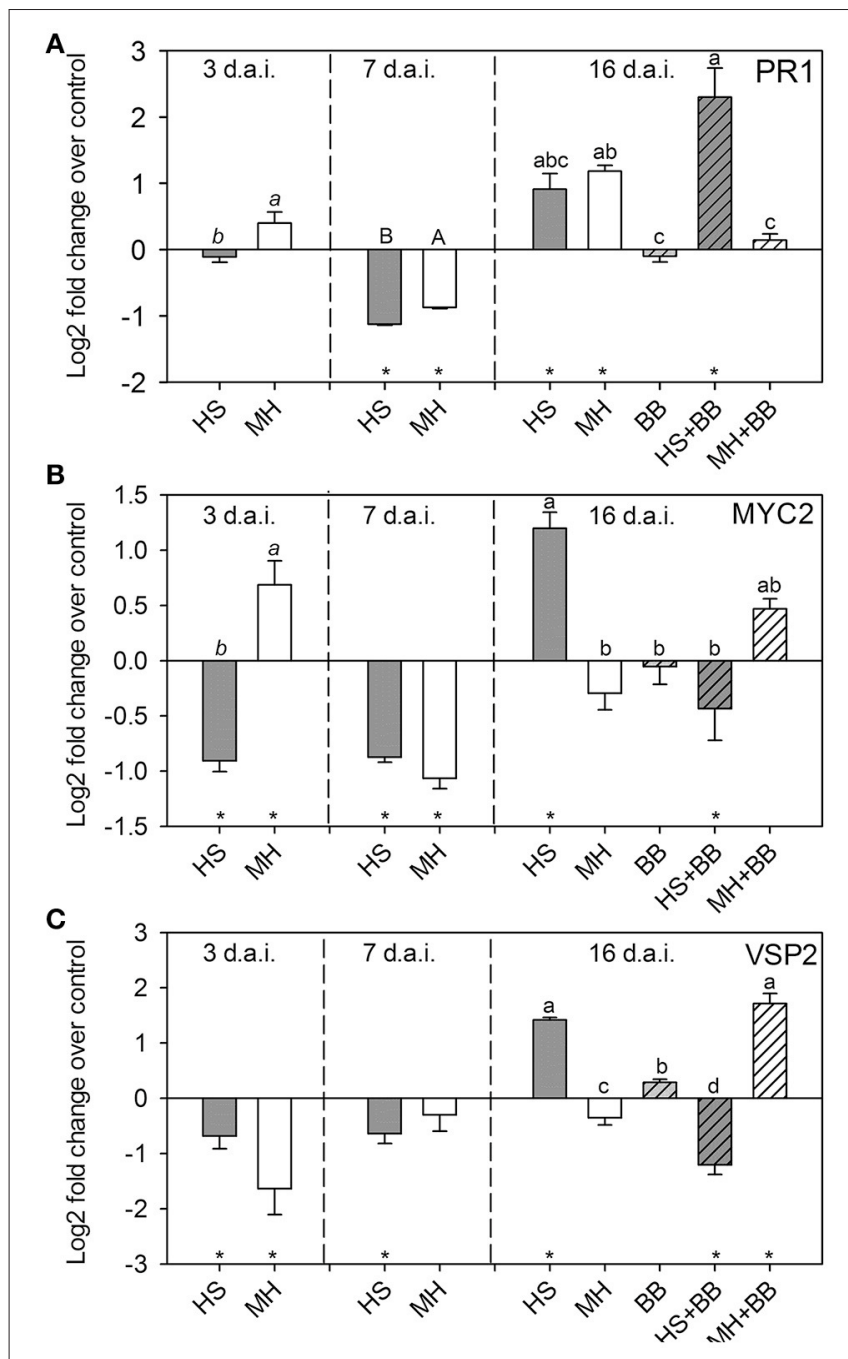

FIGURE 4 | Relative expression level (Log2) of (A) PR1, (B) MYC2, and (C) VSP2 in Brassica nigra at 3, 7, and 16 days after infestation (d.a.i.) with either Heterodera schachtii (HS) or Meloidogyne hapla (MH) nematodes. At 7 d.a.i., a subset of the plants was infested with Brevicoryne brassicae (BB) aphids-the plants with BB harvested at 16 d.a.i. suffered 9 days of aphid feeding. The expression levels were calculated over the average expression levels in control plants (mock inoculated with water) taken at each time point. Stars on the $X$-axis indicate whether the treatment significantly up -or downregulated the gene (Log2 value larger or smaller than zero; Single sample $t$-test, $p<0.005$ to correct for multiple comparisons). $N=5$ biological replicates per treatment group. Different letters over bars indicate significant differences ( 3 and 7 d.a.i.: t-tests; 16 d.a.i.; PR1: multiple comparisons test after Krusall-Wallis ANOVA; MYC2 and VSP2: Tukey HSD test after ANOVA) among treatments within harvest time point.

at 3 d.a.i. (Figure 4). H. schachtii already repressed defense marker genes at 3 d.a.i., despite the fact that feeding cell formation takes up to 5 d.a.i. (de Almeida Engler et al., 1999). Arguably, we may have missed the initial response to nematode invasion as these responses may have occurred at earlier time points (see references in Kyndt et al., 2014). However, our results obtained at 7 d.a.i, are in line with studies reporting that from this time point onwards, stress related genes, such as LOX1, ERF2, and genes coding for defenses, such as phytoalexins and protease inhibitors, were repressed in roots and shoots of nematode-infested plants (Kyndt et al., 2014). The suppression of plant immunity by nematodes may result in systemic induced susceptibility. For example, rice plants infected with M. graminincola become less resistant to the aboveground pathogen rice blast (Kyndt et al., 2017). Even though the effectors injected by root-knot and cyst nematodes greatly overlap, there may be essential differences affecting plant hormonal signaling upon invasion (Gheysen and Mitchum, 2011). For example, the establishment of the cyst nematode feeding cells involves ET signaling, whereas this is not the case for root-knot nematodes (Gheysen and Mitchum, 2011). ET in turn, can interact with both the JA and SA signaling pathways (Pieterse et al., 2009). Differences in the activation of the ET pathway thus can affect induced responses to aphids. Also after the feeding cell has been established, nematodes keep injecting effectors into the plant (Vanholme et al., 2004), thus maintaining the differences in chemical communication with their hosts.

\section{Nematodes and Aphids May Compete for Nutrients}

Our results provide evidence that interactions between defense signaling pathways may underlie the interactions between nematodes and aphids on B. nigra. However, this does not preclude that other processes play a role as well. Nematodes alter primary metabolite production and resource allocation within their host plant to enhance nutrient allocation to their feeding site (Kyndt et al., 2012a; Hol et al., 2013). Aphids also create a nutrient sink, enhancing amino acid and sugar concentrations in the phloem sap on which they feed (Cao et al., 2016; Hol et al., 2016). When nematodes and aphids feed on the same plant, it may also result in a "tug of war" for plant nutrients between the two herbivores. The outcome of this so-called "apparent competition" (Kaplan and Denno, 2007), may depend on the strength with which the first arriving herbivore, in this case the nematode, manipulates the source strength of its feeding site, the root. Further studies, analyzing transcriptomes, hormone and metabolome dynamics in roots, shoots and phloem are needed to identify how much defense responses and resource reallocation processes contribute to the observed effects.

\section{Effect of Natural Insect Behavior}

Our results also show the relevance of including natural herbivore behavior in experimental set-ups. Only when the aphids were allowed to choose, the effect of nematode infestations became evident. This is in line with the earlier observation that Myzus persicae aphids preferred nematode free A. thaliana over H. schachtii-infested plants (Kutyniok et al., 2014). Similar to our results, this study found that aphid preference correlated positively with their performance. As aphids are parthenogenetic, the number of foundresses initially colonizing the plants is greatly determining the final aphid load (Hol et al., 2016). Most studies do not allow aphids to choose among plants or even among leaves within the plant (by using clip cages, see Hoysted et al., 2017). In addition, most studies infest plants with unrealistically high numbers of aphids (e.g., 100 aphids on a single A. thaliana, De 
Vos et al., 2005) in order to obtain a strong response. Differences in herbivore loads on the plant may also explain the variance in responses that are reported (Stewart et al., 2016). Additionally, it may also explain why results obtained in the greenhouse do not always translate to field situations.

\section{Variation in Nematode Effects}

There is ample evidence to suggest that belowground herbivory by nematodes negatively affects aphid performance (Bezemer and van Dam, 2005; Wurst and van der Putten, 2007; Kaplan et al., 2009, 2011; Hong et al., 2010). However, the reported outcomes vary considerably among studies, largely due to differences in experimental designs. For example, the numbers of $\mathrm{J} 2$ nematodes added to single plants ranges from 60 (Hamamouch et al., 2011) via a 500-1,000 (Hol et al., 2013; Kutyniok et al., 2014) to 10,000 (Hoysted et al., 2017). The first half of the range likely results in realistic infestation rates found in natural plant populations (Hol et al., 2013, 2016), whereas the latter may be more indicative for infestation levels in agricultural fields (Jones et al., 2013). In addition, the responses to nematode infestation and aphids, or combinations thereof, are assessed at different time points after infestation. These range from a few days to several weeks (Bezemer and van Dam, 2005; Wurst and van der Putten, 2007; Hol et al., 2013). Last but not least, the outcome of interactions between nematodes and aphids may be affected by nutrient availability (Kutyniok and Müller, 2013; Kutyniok et al., 2014). In our experiment, we controlled for most of these factors by directly comparing the responses to, and interaction between two species of nematodes and an aphid on their natural host plant, grown on plain sand with nutrient solutions. Nevertheless, in the field, $B$. nigra is colonized by a community of nematodes (Hol et al., 2016). Experiments with plant infested by multiple nematodes conducted under (near) field conditions can reveal whether the observed systemic defense responses also affect aphid preference and performance under natural conditions (see Vandegehuchte et al. (2010).

\section{REFERENCES}

Abad, P., Gouzy, J., Aury, J.-M., Castagnone-Sereno, P., Danchin, E. G., Deleury, E., et al. (2008). Genome sequence of the metazoan plant-parasitic nematode Meloidogyne incognita. Nat. Biotechnol. 26, 909-915. doi: 10.1038/ nbt. 1482

Adie, B., Chico, J. M., Rubio-Somoza, I., and Solano, R. (2007). Modulation of plant defenses by ethylene. J. Plant Growth Regul. 26, 160-177. doi: 10.1007/s00344-007-0012-6

Beckers, G. J., and Spoel, S. H. (2006). Fine-tuning plant defence signalling: salicylate versus jasmonate. Plant Biol. 8, 1-10. doi: 10.1055/s-2005-872705.

Bezemer, T. M., and van Dam, N. M. (2005). Linking aboveground and belowground interactions via induced plant defenses. Trends Ecol. Evol. 20, 617-624. doi: 10.1016/j.tree.2005.08.006

Bidart-Bouzat, M. G., and Kliebenstein, D. (2011). An ecological genomic approach challenging the paradigm of differential plant responses to specialist versus generalist insect herbivores. Oecologia 167, 677-689. doi: $10.1007 / \mathrm{s} 00442-011-2015-\mathrm{Z}$

Biere, A., and Goverse, A. (2016). Plant-mediated systemic interactions between pathogens, parasitic nematodes, and herbivores aboveand belowground. Annu. Rev. Phytopathol. 54, 499-527. doi: 10.1146/annurev-phyto-080615-100245

\section{CONCLUSION}

We found that the root feeding plant parasitic nematodes $H$. schachtii and $M$. hapla have contrasting effects on the aboveground phloem feeding aphid B. brassicae. The identity of the nematodes determined the outcomes of the plant-mediated effects on aphid preference and performance. Differences in hormonal pathways involved in induced plant responses were found to play a role. Our findings may be particularly relevant to agro-ecosystems, where usually one species of nematode is dominating pest in a crop. It is yet to be assessed how signaling pathways interact when multiple nematodes infest a plant, as is common in natural environments.

\section{AUTHOR CONTRIBUTIONS}

TT designed the study together with MW and NvD. MW carried out the experiments under direct supervision of TT. VM and $\mathrm{NvD}$ performed statistical analyses. MW wrote most of the Materials and Methods section. NvD, VM, and TT wrote the rest of the manuscript and prepared it for publication.

\section{FUNDING}

NvD gratefully acknowledges the support of the German Centre for Integrative Biodiversity Research (iDiv) Halle-Jena-Leipzig funded by the German Research Foundation (FZT 118). MW was supported by an Erasmus Mundus fellowship for the European Master of Science in Nematology (EUMAINE).

\section{ACKNOWLEDGMENTS}

The authors thank the greenhouse staff of Radboud University Nijmegen, Rob de Graaf, Fikirte Mamo Offiga, Onno W. Calf, and Nadia van Bronckhorst-Marttin for their support with the experiments.
Cao, H. H., Liu, H. R., Zhang, Z. F., and Liu, T. X. (2016). The green peach aphid Myzus persicae perform better on pre-infested Chinese cabbage Brassica pekinensis by enhancing host plant nutritional quality. Sci. Rep. 6:21954. doi: $10.1038 /$ srep21954.

Danner, H., Desurmont, G. A., Cristescu, S. M., and Dam, N. M. (2017). Herbivore-induced plant volatiles accurately predict history of coexistence, diet breadth, and feeding mode of herbivores. New Phytol. doi: 10.1111/nph.14428. [Epub ahead of print].

de Almeida Engler, J., De Vleesschauwer, V., Burssens, S., Celenza, J. L., Inze, D., Van Montagu, M., et al. (1999). Molecular markers and cell cycle inhibitors show the importance of cell cycle progression in nematode-induced galls and syncytia. Plant Cell 11, 793-807. doi: 10.1105/tpc.11.5.793

De Vos, M., and Jander, G. (2009). Myzus persicae (green peach aphid) salivary components induce defence responses in Arabidopsis thaliana. Plant Cell Environ. 32, 1548-1560. doi: 10.1111/j.1365-3040.2009.02019.x

De Vos, M., Van Oosten, V. R., Van Poecke, R. M., Van Pelt, J. A., Pozo, M. J., Mueller, M. J., et al. (2005). Signal signature and transcriptome changes of Arabidopsis during pathogen and insect attack. Mol. Plant Microbe Interact. 18, 923-937. doi: 10.1094/MPMI-18-0923

Dicke, M., and Baldwin, I. T. (2010). The evolutionary context for herbivoreinduced plant volatiles: beyond the 'cry for help'. Trends Plant Sci. 15, 167-175. doi: 10.1016/j.tplants.2009.12.002 
Erb, M., Flors, V., Karlen, D., De Lange, E., Planchamp, C., D’Alessandro, M., et al. (2009). Signal signature of aboveground-induced resistance upon belowground herbivory in maize. Plant J. 59, 292-302. doi: 10.1111/j.1365-313X.2009.03868.x

Erb, M., Robert, C. A., Hibbard, B. E., and Turlings, T. C. (2011). Sequence of arrival determines plant-mediated interactions between herbivores. J. Ecol. 99, 7-15. doi: 10.1111/j.1365-2745.2010.01757.x

Francis, F., Lognay, G., Wathelet, J.-P., and Haubruge, E. (2001). Effects of alleleochemicals from first (Brassicaceae) and second (Myzus persicae and Brevicoryne brassicae) trophic levels on Adalia bipunctata. J. Chem. Ecol. 27, 243-256. doi: 10.1023/A:1005672220342

$\mathrm{Fu}, \mathrm{Z}$. Q., and Dong, X. N. (2013). "Systemic acquired resistance: Turning local infection into global defense," in Annual Review of Plant Biology, Vol 64, ed S.S. Merchant (Palo Alto: Annual Reviews), 839-863.

Gheysen, G., and Mitchum, M. G. (2011). How nematodes manipulate plant development pathways for infection. Curr. Opin. Plant Biol. 14, 415-421. doi: 10.1016/j.pbi.2011.03.012

Haegeman, A., Mantelin, S., Jones, J. T., and Gheysen, G. (2012). Functional roles of effectors of plant-parasitic nematodes. Gene 492, 19-31. doi: 10.1016/j.gene.2011.10.040

Hamamouch, N., Li, C. Y., Seo, P. J., Park, C. M., and Davis, E. L. (2011). Expression of Arabidopsis pathogenesis-related genes during nematode infection. Mol. Plant Pathol. 12, 355-364. doi: 10.1111/j.1364-3703.2010.00675.x

Hogenhout, S. A., and Bos, J. I. B. (2011). Effector proteins that modulate plant-insect interactions. Curr. Opin. Plant Biol. 14, 422-428. doi: 10.1016/j.pbi.2011.05.003

Hol, W. H., De Boer, W., Termorshuizen, A. J., Meyer, K. M., Schneider, J. H., Putten, W. H., et al. (2013). Heterodera schachtii nematodes interfere with aphid-plant relations on Brassica oleracea. J. Chem. Ecol. 39, 1193-1203. doi: 10.1007/s10886-013-0338-4

Hol, W. H., Raaijmakers, C. E., Mons, I., Meyer, K. M., and van Dam, N. M. (2016). Root-lesion nematodes suppress cabbage aphid population development by reducing aphid daily reproduction. Front. Plant Sci. 7:111. doi: $10.3389 /$ fpls.2016.00111

Hong, S. C., Donaldson, J., and Gratton, C. (2010). Soybean cyst nematode effects on soybean aphid preference and performance in the laboratory. Environ. Entomol. 39, 1561-1569. doi: 10.1603/EN10091

Hoysted, G. A., Lilley, C. J., Field, K. J., Dickinson, M., Hartley, S. E., and Urwin, P. E. (2017). A plant-feeding nematode indirectly increases the fitness of an aphid. Front. Plant Sci. 8:1897. doi: 10.3389/fpls.2017.01897

Jones, J. T., Haegeman, A., Danchin, E. G., Gaur, H. S., Helder, J., Jones, M. K., et al. (2013). Top 10 plant-parasitic nematodes in molecular plant pathology. Mol. Plant Pathol. 14, 946-961. doi: 10.1111/mpp.12057

Kafle, D., Hänel, A., Lortzing, T., Steppuhn, A., and Wurst, S. (2017). Sequential above-and belowground herbivory modifies plant responses depending on herbivore identity. BMC Ecol. 17:5. doi: 10.1186/s12898-017-0115-2

Kaplan, I., and Denno, R. F. (2007). Interspecific interactions in phytophagous insects revisited: a quantitative assessment of competition theory. Ecol. Lett. 10, 977-994. doi: 10.1111/j.1461-0248.2007.01093.x

Kaplan, I., Sardanelli, S., and Denno, R. F. (2009). Field evidence for indirect interactions between foliar-feeding insect and root-feeding nematode communities on Nicotiana tabacum. Ecol. Entomol. 34, 262-270. doi: 10.1111/j.1365-2311.2008.01062.x

Kaplan, I., Sardanelli, S., Rehill, B. J., and Denno, R. F. (2011). Toward a mechanistic understanding of competition in vascular-feeding herbivores: an empirical test of the sink competition hypothesis. Oecologia 166, 627-636. doi: $10.1007 / \mathrm{s} 00442-010-1885-9$

Karban, R. (2011). The ecology and evolution of induced resistance against herbivores. Funct. Ecol. 25, 339-347. doi: 10.1111/j.1365-2435.2010.01789.x

Karban, R., and Baldwin, I. T. (1997). Induced Responses to Herbivory. Chicago, IL: University of Chicago Press.

Koornneef, A., and Pieterse, C. M. J. (2008). Cross talk in defense signaling. Plant Physiol. 146, 839-844. doi: 10.1104/pp.107.112029

Kos, M., Broekgaarden, C., Kabouw, P., Lenferink, K. O., Poelman, E. H., Vet, L. E. M., et al. (2011). Relative importance of plant-mediated bottom-up and top-down forces on herbivore abundance on Brassica oleracea. Funct. Ecol. 25, 1113-1124. doi: 10.1111/j.1365-2435.2011.01871.x
Kuśnierczyk, A., Winge, P., Jorstad, T. S., Troczynska, J., Rossiter, J. T., and Bones, A. M. (2008). Towards global understanding of plant defence against aphids - timing and dynamics of early Arabidopsis defence responses to cabbage aphid (Brevicoryne brassicae) attack. Plant Cell Environ. 31, 1097-1115. doi: 10.1111/j.1365-3040.2008.01823.x

Kutyniok, M., and Müller, C. (2012). Crosstalk between above- and belowground herbivores is mediated by minute metabolic responses of the host Arabidopsis thaliana. J. Exp. Bot. 63, 6199-6210. doi: 10.1093/jxb/ers274

Kutyniok, M., and Müller, C. (2013). Plant-mediated interactions between shootfeeding aphids and root-feeding nematodes depend on nitrate fertilization. Oecologia 173, 1367-1377. doi: 10.1007/s00442-013-2712-x

Kutyniok, M., Persicke, M., and Müller, C. (2014). Effects of root herbivory by nematodes on the performance and preference of a leaf-infesting generalist aphid depend on nitrate fertilization. J. Chem. Ecol. 40, 118-127. doi: 10.1007/s10886-014-0387-3

Kyndt, T., Denil, S., Bauters, L., Van Criekinge, W., and De Meyer, T. (2014). Systemic suppression of the shoot metabolism upon rice root nematode infection. PLOS ONE 9:e106858. doi: 10.1371/journal.pone.0106858

Kyndt, T., Denil, S., Haegeman, A., Trooskens, G., Bauters, L., Van Criekinge, W., et al. (2012a). Transcriptional reprogramming by root knot and migratory nematode infection in rice. New Phytol. 196, 887-900. doi: 10.1111/j.1469-8137.2012.04311.x

Kyndt, T., Nahar, K., Haegeman, A., De Vleesschauwer, D., Hofte, M., and Gheysen, G. (2012b). Comparing systemic defence-related gene expression changes upon migratory and sedentary nematode attack in rice. Plant Biol. 14, 73-82. doi: 10.1111/j.1438-8677.2011.00524.x

Kyndt, T., Zemene, H. Y., Haeck, A., Singh, R., De Vleesschauwer, D., Deni, S., et al. (2017). Below-ground attack by the root knot nematode Meloidogyne graminicola predisposes rice to blast disease. Mol. Plant-Microbe Interact. 30, 255-266. doi: 10.1094/mpm1-11-16-0225-r

Lancashire, P. D., Bleiholder, H., Vandenboom, T., Langeluddeke, P., Stauss, R., Weber, E., et al. (1991). A unifrom decimal code for growth stages of crops and weeds. Ann. Appl. Biol. 119, 561-601. doi: 10.1111/j.1744-7348.1991.tb04895.x

Leon-Reyes, A., Spoel, S. H., De Lange, E. S., Abe, H., Kobayashi, M., Tsuda, S., et al. (2009). Ethylene modulates the role of NONEXPRESSOR OF PATHOGENESIS-RELATED GENES1 in cross talk between salicylate and jasmonate signaling. Plant Physiol. 149, 1797-1809. doi: 10.1104/pp.108.133926

Martinez-Medina, A., Flors, V., Heil, M., Mauch-Mani, B., Pieterse, C. M., Pozo, M. J., et al. (2016). Recognizing plant defense priming. Trends Plant Sci. 21, 818-822. doi: 10.1016/j.tplants.2016.07.009

Mathur, V., Ganta, S., Raaijmakers, C. E., Reddy, A. S., Vet, L. E., and van Dam, N. M. (2011). Temporal dynamics of herbivore-induced responses in Brassica juncea and their effect on generalist and specialist herbivores. Entomol. Exp. Appl. 139, 215-225. doi: 10.1111/j.1570-7458.2011.01122.x

Mathur, V., Tytgat, T. O. G., Hordijk, C. A., Harhangi, H. R., Jansen, J. J., Reddy, A. S., et al. (2013a). An ecogenomic analysis of herbivore induced plant volatiles in Brassica juncea. Mol. Ecol. 22, 6179-6196. doi: 10.1111/mec.12555

Mathur, V., Wagenaar, R., Caissard, J. C., Reddy, A. S., Vet, L. E., Cortesero, A.-M., et al. (2013b). A novel indirect defence in Brassicaceae: structure and function of extrafloral nectaries in Brassica juncea. Plant Cell Environ. 36, 528-541. doi: 10.1111/j.1365-3040.2012.02593.x

Miles, P. W. (1999). Aphid saliva. Biol. Rev. 74, 41-85. doi: 10.1017/S0006323198005271

Mithöfer, A., and Boland, W. (2008). Recognition of herbivory-associated molecular patterns. Plant Physiol. 146, 825-831. doi: 10.1104/pp.107.113118

Moran, P. J., Cheng, Y. F., Cassell, J. L., and Thompson, G. A. (2002). Gene expression profiling of Arabidopsis thaliana in compatible plant-aphid interactions. Arch. Insect Biochem. Physiol. 51, 182-203. doi: $10.1002 /$ arch.10064

Muller, P. Y., Janovjak, H., Miserez, A. R., and Dobbie, Z. (2002). Processing of gene expression data generated by quantitative real-time RT-PCR. Biotechniques 32, 1372-1374. Available online at: http://www.qpcrupdate.com/muller-2002qgene.pdf

Nour-Eldin, H. H., Andersen, T. G., Burow, M., Madsen, S. R., Jorgensen, M. E., Olsen, C. E., et al. (2012). NRT/PTR transporters are essential for translocation of glucosinolate defence compounds to seeds. Nature 488, 531-534. doi: 10.1038/nature11285 
Papadopoulou, G. V., and van Dam, N. M. (2017). Mechanisms and ecological implications of plant-mediated interactions between belowground and aboveground insect herbivores. Ecol. Res. 32, 13-26. doi: $10.1007 / \mathrm{s} 11284-016-1410-7$

Pieterse, C. M. (2012). Prime time for transgenerational defense. Plant Physiol. 158:545. doi: 10.1104/pp.112.900430

Pieterse, C. M., Leon-Reyes, A., Van der Ent, S., and Van Wees, S. C. (2009). Networking by small-molecule hormones in plant immunity. Nat. Chem. Biol. 5, 308-316. doi: 10.1038/nchembio. 164

Ramakers, C., Ruijter, J. M., Deprez, R. H. L., and Moorman, A. F. M. (2003). Assumption-free analysis of quantitative real-time polymerase chain reaction (PCR) data. Neurosci. Lett. 339, 62-66. doi: 10.1016/s0304-3940(02) 01423-4

Sasser, J. N. (1989). Plant Parasitic Nematodes: The Farmer's Hidden Enemy. Raleigh, NC: Department of Plant Pathology, North Carolina State University.

Sokal, R. R., and Rohlf, J. F. (1995). Biometry: the Principles and Practice of Statistics in Biological Research. New York, NY: Freeman and Co.

Stewart, S. A., Hodge, S., Bennett, M., Mansfield, J. W., and Powell, G. (2016). Aphid induction of phytohormones in Medicago truncatula is dependent upon time post-infestation, aphid density and the genotypes of both plant and insect. Arthropod Plant Interact. 10, 41-53. doi: 10.1007/s11829-015-9406-8

van Dam, N. M., and Heil, M. (2011). Multitrophic interactions below and above ground: en route to the next level. J. Ecol. 99, 77-88. doi: 10.1111/j.1365-2745.2010.01761.x

van Dam, N. M., and Oomen, M. W. A. T. (2008). Root and shoot jasmonic acid applications differentially affect leaf chemistry and herbivore growth. Plant Signal. Behav. 3, 91-98. doi: 10.4161/psb.3.2.5220

van Dam, N. M., Witjes, L., and Svatos, A. (2004). Interactions between aboveground and belowground induction of glucosinolates in two wild Brassica species. New Phytol. 161, 801-810. doi: 10.1111/j.1469-8137.2004. 00984.x

Vandegehuchte, M. L., de la Pe-a, E., and Bonte, D. (2010). Interactions between root and shoot herbivores of Ammophila arenaria in the laboratory do not translate into correlated abundances in the field. Oikos 119, 1011-1019. doi: 10.1111/j.1600-0706.2009.18360.x

Vandesompele, J., De Preter, K., Pattyn, F., Poppe, B., Van Roy, N., De Paepe, A., et al. (2002). Accurate normalization of real-time quantitative RT-PCR data by geometric averaging of multiple internal control genes. Genome Biol. 3:RESEARCH0034. doi: 10.1186/gb-2002-3-7-research0034 van Geem, M., Gols, R., Raaijmakers, C. E., and Harvey, J. A. (2016). Effects of population-related variation in plant primary and secondary metabolites on aboveground and belowground multitrophic interactions. Chemoecology 26, 219-233. doi: 10.1007/s00049-016-0222-0

Vanholme, B., De Meutter, J., Tytgat, T., Van Montagu, M., Coomans, A., and Gheysen, G. (2004). Secretions of plant-parasitic nematodes: a molecular update. Gene 332, 13-27. doi: 10.1016/j.gene.2004.02.024

Verhage, A., Vlaardingerbroek, I., Raaijmakers, C., Van Dam, N., Dicke, M., Van Wees, S. C., et al. (2011). Rewiring of the jasmonate signaling pathway in Arabidopsis during insect herbivory. Front. Plant Sci. 2:47. doi: 10.3389/fpls.2011.00047

Walling, L. L. (2000). The myriad plant responses to herbivores. J. Plant Growth Regul. 19, 195-216. doi: 10.1007/s003440000026

Wasternack, C. (2014). Action of jasmonates in plant stress responses and development-applied aspects. Biotechnol. Adv. 32, 31-39. doi: 10.1016/j.biotechadv.2013.09.009

Williamson, V. M., and Gleason, C. A. (2003). Plant-nematode interactions. Curr. Opin. Plant Biol. 6, 327-333. doi: 10.1016/S1369-5266(03)00059-1

Williamson, V. M., and Kumar, A. (2006). Nematode resistance in plants: the battle underground. Trends Genet. 22, 396-403. doi: 10.1016/j.tig.2006.05.003

Wurst, S., van Dam, N. M., Monroy, F., Biere, A., and van der Putten, W. H. (2008), Intraspecific variation in plant defense alters effects of root herbivores on leaf chemistry and aboveground herbivore damage. J. Chem. Ecol. 34, 1360-1367. doi: 10.1007/s10886-008-9537-9

Wurst, S., and van der Putten, W. H. (2007). Root herbivore identity matters in plant-mediated interactions between root and shoot herbivores. Basic Appl. Ecol. 8, 491-499. doi: 10.1016/j.baae.2006.09.015

Conflict of Interest Statement: The authors declare that the research was conducted in the absence of any commercial or financial relationships that could be construed as a potential conflict of interest.

Copyright (c) 2018 van Dam, Wondafrash, Mathur and Tytgat. This is an open-access article distributed under the terms of the Creative Commons Attribution License (CC $B Y)$. The use, distribution or reproduction in other forums is permitted, provided the original author(s) and the copyright owner are credited and that the original publication in this journal is cited, in accordance with accepted academic practice. No use, distribution or reproduction is permitted which does not comply with these terms. 